\title{
cFFR as an alternative to FFR: please do not contrast simplicity!
}

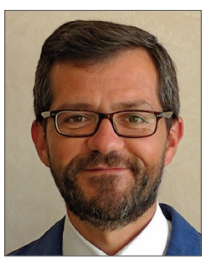

Antonio Maria Leone ${ }^{1 *}$, MD; Pio Cialdella1, MD; Roberto Martin-Reyes ${ }^{2}, \mathrm{MD}$; Sergio Baptista ${ }^{3}, \mathrm{MD}$; Nicolas Amabile ${ }^{4}, \mathrm{MD}$; Luis Raposo 5 , MD

1. Institute of Cardiology, Catholic University of the Sacred Heart, Rome, Italy; 2. Unidad de Cardiologia Intervencionista, Servicio de Cardiologia, Hospital Universitario Fundacion Jimenez Diaz-IDC Salud, Madrid, Spain; 3. Department of Cardiology, Hospital Prof. Doutor Fernando Fonseca, Amadora, Portugal; 4. Department of Cardiology, L'Institut Mutualiste Montsouris, Paris, France; 5. Department of Cardiology, Centro Hospitalar de Lisboa Ocidental, Lisbon, Portugal

We thank Macaya et $\mathrm{al}^{1}$ for their interest in the MEMENTO-FFR study because it provides us with an additional opportunity to explain better the conclusions and implications for clinical practice of our study ${ }^{2}$. First of all, Macaya et al raised some concern on the design of the study and in particular the fact that FFR was considered the standard reference. In this regard, the design of the MEMENTO-FFR is not different from a number of other studies, namely on the ability of iFR to predict FFR ${ }^{3,4}$. We agree with their opinion that FFR is not infallible; nevertheless, we think that everyone would also acknowledge that, at present, FFR is the most validated invasive tool for diagnosing a functionally significant coronary artery stenosis in the catheterisation laboratory. Accordingly, in the current ESC guidelines for coronary revascularisation, FFR has received a class IA recommendation to assess the functional significance of a coronary stenosis when evidence of ischaemia is lacking 5 . Moreover, while in the early stages FFR was validated in comparison to several noninvasive techniques ${ }^{6}$, now it has become the reference standard against which non-invasive tests are compared ${ }^{7}$. All these considerations, in addition to the prognostic value and the ability to allocate the appropriate treatment correctly ${ }^{8}$, explain why FFR is now perceived by the general (including non-interventional) cardiology community as a cornerstone in the diagnosis of coronary artery disease. Consequently, although we cannot dismiss the possibility that, in the (near) future, other indices (including
cFFR) can achieve comparable efficiency, it is quite surprising that FFR is so strongly questioned by these very renowned interventional cardiologists.

A second potential concern, raised by the readers, is related to the similarity of the measured indices $(\mathrm{Pd} / \mathrm{Pa}$ and, more importantly, cFFR) with FFR. In our opinion, the evidence that cFFR is very similar to FFR is not a weakness but rather a strength of cFFR. In the annoying battle to find an accurate and simple surrogate for FFR, we have to bear in mind the starting point. This was the need to simplify and speed up the procedure in order to expand the use of functional evaluation of coronary stenosis in the real world, especially for those who, for financial, logistic or other reasons, cannot (or do not want to) use adenosine. For this purpose, given its accuracy and similarity to conventional "adenosine-based" FFR, cFFR is, in our opinion, a valuable and costeffective option. In addition, iFR, which, in the opinion of Macaya et al, is "mechanistically different from FFR, Pd/Pa and cFFR", was originally proposed by Sen et al to circumvent the use of adenosine, hypothesising that during the cardiac cycle "there is a time when resistance is naturally minimised at rest" and consequently that no vasodilator would be needed ${ }^{9}$. Unfortunately, this is not the case, as iFR during administration of adenosine is significantly reduced, showing that resistance can be lowered further also during the so-called "wave-free period" 10,11 . Basically, as we clearly state in the MEMENTO-FFR paper, cFFR is a simple way

*Corresponding author: Area Cardiovascolare, Fondazione Policlinico Universitario Agostino Gemelli, Largo Agostino Gemelli 8, 
of inducing a somewhat lower degree of hyperaemia that could be enough for disclosing "significant" lesions in an important proportion of cases, thus circumventing the use of adenosine.

While we know from CONTRAST and MEMENTO-FFR that cFFR performs better than resting indices in predicting $\mathrm{FFR}^{2,11}$, at this point we cannot answer the question which index (FFR, iFR, cFFR or whatever) could perform better in a study that would use another independent reference standard or other clinical endpoints. This is an interesting point that still needs to be adequately demonstrated. Concerning iFR, we look forward to the upcoming results of very important clinical trials and, hopefully, to seeing replicated the vast amount of clinical evidence accumulated by FFR. In the meantime, we think that, despite the fact that the comparison of cFFR and iFR (which we do not test in our study at all) could be viewed like "comparing apples and pears", this is what everyone does in everyday life in the cathlab. We bet that a hungry operator, coming out from a complex procedure, will choose from the fruit basket a fresh Red Delicious apple, very similar to his favourite Golden Delicious, instead of an anonymous rotten pear!

\section{Conflict of interest statement}

A.M. Leone has received speaking honoraria from St. Jude Medical. S. Baptista has received investigation grants from St. Jude Medical. N. Amabile has received consulting honoraria from St. Jude Medical. L. Raposo has received investigation grants from St. Jude Medical and speaker fees from St. Jude Medical and Volcano Corp. The other authors have no conflicts of interest to declare.

\section{References}

1. Macaya F, Cerrato E, Mejía-Rentería H, Ruan N, Salinas P, Núñez-Gil I, Escaned J. cFFR as an alternative to FFR: does the contrast still need to be contrasted? EuroIntervention. 2017;12:2278-9.

2. Leone AM, Martin-Reyes R, Baptista SB, Amabile N, Raposo L, Franco Pelaez JA, Trani C, Cialdella P, Basile E, Zimbardo G, Burzotta F, Porto I, Aurigemma C, Rebuzzi AG, Faustino M, Niccoli G, Abreu PF, Slama MS, Spagnoli V, Telleria Arrieta M, Amat Santos IJ, de la Torre Hernandez JM, Lopez Palop R, Crea F. The Multi-center Evaluation of the Accuracy of the Contrast MEdium INduced Pd/Pa RaTiO in Predicting FFR (MEMENTO-FFR) Study. EuroIntervention. 2016;12:708-15.

3. Sen S, Escaned J, Malik IS, Mikhail GW, Foale RA, Mila R, Tarkin J, Petraco R, Broyd C, Jabbour R, Sethi A, Baker CS, Bellamy M, Al-Bustami M, Hackett D, Khan M, Lefroy D, Parker KH, Hughes AD, Francis DP, Di Mario C, Mayet J, Davies JE. Development and validation of a new adenosine-independent index of stenosis severity from coronary wave-intensity analysis: results of the ADVISE (ADenosine Vasodilator Independent Stenosis Evaluation) study. J Am Coll Cardiol. 2012;59:1392-402.

4. Jeremias A, Maehara A, Généreux P, Asrress KN, Berry C, De Bruyne B, Davies JE, Escaned J, Fearon WF, Gould KL, Johnson NP, Kirtane AJ, Koo BK, Marques KM, Nijjer S, Oldroyd KG, Petraco R, Piek JJ, Pijls NH, Redwood S, Siebes M,
Spaan JA, van 't Veer M, Mintz GS, Stone GW. Multicenter core laboratory comparison of the instantaneous wave-free ratio and resting $\mathrm{Pd} / \mathrm{Pa}$ with fractional flow reserve: the RESOLVE study. J Am Coll Cardiol. 2014;63:1253-61.

5. Windecker S, Kolh P, Alfonso F, Collet JP, Cremer J, Falk V, Filippatos G, Hamm C, Head SJ, Jüni P, Kappetein AP, Kastrati A, Knuuti J, Landmesser U, Laufer G, Neumann FJ, Richter DJ, Schauerte P, Sousa Uva M, Stefanini GG, Taggart DP, Torracca L, Valgimigli M, Wijns W, Witkowski A. 2014 ESC/EACTS Guidelines on myocardial revascularization: The Task Force on Myocardial Revascularization of the European Society of Cardiology (ESC) and the European Association for Cardio-Thoracic Surgery (EACTS) Developed with the special contribution of the European Association of Percutaneous Cardiovascular Interventions (EAPCI). Eur Heart J. 2014;35:2541-619.

6. De Bruyne B, Sarma J. Fractional flow reserve: a review: invasive imaging. Heart. 2008;94:949-59.

7. Danad I, Szymonifka J, Twisk JW, Norgaard BL, Zarins CK, Knaapen P, Min JK. Diagnostic performance of cardiac imaging methods to diagnose ischaemia-causing coronary artery disease when directly compared with fractional flow reserve as a reference standard: a meta-analysis. Eur Heart J. 2017;38:991-8.

8. Baptista SB, Raposo L, Santos L, Ramos R, Calé R, Jorge E, Machado C, Costa M, Infante de Oliveira E, Costa J, Pipa J, Fonseca N, Guardado J, Silva B, Sousa MJ, Silva JC, Rodrigues A, Seca L, Fernandes R. Impact of Routine Fractional Flow Reserve Evaluation During Coronary Angiography on Management Strategy and Clinical Outcome: One-Year Results of the POST-IT. Circ Cardiovasc Interv. $2016 \mathrm{Jul} ; 9(7)$.

9. Sen S, Asrress KN, Nijjer S, Petraco R, Malik IS, Foale RA, Mikhail GW, Foin N, Broyd C, Hadjiloizou N, Sethi A, Al-Bustami M, Hackett D, Khan MA, Khawaja MZ, Baker CS, Bellamy M, Parker KH, Hughes AD, Francis DP, Mayet J, Di Mario C, Escaned J, Redwood S, Davies JE. Diagnostic classification of the instantaneous wave-free ratio is equivalent to fractional flow reserve and is not improved with adenosine administration. Results of CLARIFY (Classification Accuracy of Pressure-Only Ratios Against Indices Using Flow Study). J Am Coll Cardiol. 2013;61:1409-20.

10. Berry C, van 't Veer M, Witt N, Kala P, Bocek O, Pyxaras SA, McClure JD, Fearon WF, Barbato E, Tonino PA, De Bruyne B, Pijls NH, Oldroyd KG. VERIFY (VERification of Instantaneous Wave-Free Ratio and Fractional Flow Reserve for the Assessment of Coronary Artery Stenosis Severity in EverydaY Practice): a multicenter study in consecutive patients. J Am Coll Cardiol. 2013;61: 1421-7.

11. Johnson NP, Jeremias A, Zimmermann FM, Adjedj J, Witt N, Hennigan B, Koo BK, Maehara A, Matsumura M, Barbato E, Esposito G, Trimarco B, Rioufol G, Park SJ, Yang HM, Baptista SB, Chrysant GS, Leone AM, Berry C, De Bruyne B, Gould KL, Kirkeeide RL, Oldroyd KG, Pijls NH, Fearon WF. Continuum of Vasodilator Stress From Rest to Contrast Medium to Adenosine Hyperemia for Fractional Flow Reserve Assessment. JACC Cardiovasc Interv. 2016;9:757-67. 